Research

\title{
Population structure of the malaria vector Anopheles moucheti in the equatorial forest region of Africa Christophe Antonio-Nkondjio*1, Cyrille Ndo ${ }^{1,3}$, Pierre Kengne ${ }^{2}$, Louis Mukwaya ${ }^{4}$, Parfait Awono-Ambene ${ }^{1}$, Didier Fontenille ${ }^{2}$ and Frédéric Simard ${ }^{1,2}$
}

Address: ${ }^{1}$ Laboratoire de Recherche sur le Paludisme, Organisation de Coordination pour la Lutte contre les Endémies en Afrique Centrale (OCEAC), P.O. Box 288, Yaoundé, Cameroon, ${ }^{2}$ Laboratoire de lutte contre les Insectes Nuisibles, Institut de Recherche pour le Développement (IRD), UR 016, 911, avenue Agropolis, P.O. Box 64501, 34394 Montpellier cedex 5, France, ${ }^{3}$ Faculty of Sciences, University of Yaoundé I, P.O. Box 337, Yaoundé, Cameroon and ${ }^{4}$ Entomology Division, Uganda Virus Research Institute, P.O. Box 49, Entebbe, Uganda

Email: Christophe Antonio-Nkondjio* - antonio_nk@yahoo.fr; Cyrille Ndo - cyrndo@yahoo.fr; Pierre Kengne - kengne@ird.fr; Louis Mukwaya - mukwayal@imul.com; Parfait Awono-Ambene - ambene_69@yahoo.fr; Didier Fontenille - fontenil@mpl.ird.fr; Frédéric Simard - simard@ird.fr

* Corresponding author

Published: 4 July 2008

Malaria Journal 2008, 7:120 doi:10.1186/1475-2875-7-120
Received: 7 April 2008

Accepted: 4 July 2008

This article is available from: http://www.malariajournal.com/content/7///I20

(C) 2008 Antonio-Nkondjio et al; licensee BioMed Central Ltd.

This is an Open Access article distributed under the terms of the Creative Commons Attribution License (http://creativecommons.org/licenses/by/2.0), which permits unrestricted use, distribution, and reproduction in any medium, provided the original work is properly cited.

\begin{abstract}
Background: Anopheles moucheti is a major malaria vector in forested areas of Africa. However, despite its important epidemiological role, it remains poorly known and insufficiently studied. Here, levels of genetic differentiation were estimated between different $A$. moucheti populations sampled throughout its distribution range in Central Africa.
\end{abstract}

Methods: Polymorphism at ten microsatellite markers was compared in mosquitoes sampled in Cameroon, the Democratic Republic of Congo and an island on Lake Victoria in Uganda. Microsatellite data were used to estimate genetic diversity within populations, their relative longterm effective population size, and the level of genetic differentiation between them.

Results: All specimens collected in Tsakalakuku (Democratic Republic of Congo) were identified as $A$. $m$. bervoetsi while other samples consisted of $A$. m. moucheti. Successful amplification was obtained at all microsatellite loci within all $A$. m. moucheti samples while only six loci amplified in $A$. $m$. bervoetsi. Allelic richness and heterozygosity were high for all populations except the island population of Uganda and A. m. bervoetsi. High levels of genetic differentiation were recorded between $A$. $m$. bervoetsi and each $A$. m. moucheti sample as well as between the island population of A. m. moucheti and mainland populations. Significant isolation by distance was evidenced between mainland populations.

Conclusion: High levels of genetic differentiation supports complete speciation of $A$. m. bervoetsi which should henceforth be recognized as a full species and named $A$. bervoetsi. Isolation by distance is the main force driving differentiation between mainland populations of $A$. $m$. moucheti. Genetically and geographically isolated populations exist on Lake Victoria islands, which might serve as relevant field sites for evaluation of innovative vector control strategies. 


\section{Background}

Malaria remains one of the world's major health problems claiming at least one million deaths each year in Africa [1]. In the forested areas of equatorial Africa, where malaria transmission occurs all year long, Anopheles moucheti mosquitoes can sustain malaria transmission intensities as high as 100-300 infected bites per man per year in villages located at the vicinity of large rivers and slowmoving streams where its larvae develop [2-5]. However, despite playing such an important epidemiological role in malaria transmission, this group of mosquitoes remains poorly known and insufficiently studied. Data on its bionomics and genetic structure are currently lacking although such data are of paramount importance for a comprehensive implementation and monitoring of malaria vector control in Central Africa [6].

Anopheles moucheti is a group of three morphological forms: A. moucheti moucheti, A. moucheti nigeriensis and A. moucheti bervoetsi, which can be distinguished by minor variations in the size and distribution of pale fringe spots and pale vein spots on the wings at the adult stage, and at the larval stage by the number of branches of the saddle hair ( $>5$ branches for A. $m$. bervoetsi and $<5$ branches for the two others) $[7,8]$. However, population genetics studies using allozyme markers revealed that these morphological variations were not segregating between the different taxonomic units that build up the A. mouchet group in Central Africa and were therefore of poor diagnostic value [9]. More recently, DNA sequence differences were detected in the mitochondrial gene encoding the cytochrome B (CytB) and the ribosomal DNA Internal Transcribed Spacers (ITS) 1 and 2 between specimens of A. m. moucheti, A. m. nigeriensis and A. m. bervoetsi and a diagnostic PCR assay was subsequently developed allowing straightforward identification of the three taxonomic units within the A. moucheti group [10]. This study further suggested that $A$. m. moucheti is widespread throughout the forested areas of Central Africa, whereas A. m. nigeriensis and A. m. bervoetsi were found only in their type localities in Nigeria and the Democratic Republic of Congo (DRC), respectively. Microsatellite DNA markers have been isolated from A. moucheti [11] and these were demonstrated to be suitable tools for population genetics studies within this group of mosquitoes [12]. Very low levels of genetic differentiation (Fst<0.0275) were detected between $A$. moucheti populations situated 65$400 \mathrm{~km}$ apart in Cameroon, suggesting high levels of gene flow at this geographical scale [12].

Previous findings from Cameroon [12] are expanded through the inclusion of mosquitoes sampled in DRC and Uganda, to further explore the level of genetic structuring between populations of the A. moucheti group and to precise the taxonomic status of An. m. bervoetsi. Analytical methods, based on various aspects of the data, are used to provide insights into the role and relative importance of geographic distance, demographic parameters (eg effective population size and demographic instability) and natural barriers to gene flow such as habitat discontinuities and speciation in shaping the observed population structure.

\section{Methods \\ Mosquitoes sampling and collection sites}

The mosquito samples obtained from four villages in Cameroon that were used in this study were described in details previously [12]. Additional adult mosquitoes were collected by pyrethrum spray catches and/or bednet traps from two villages in DRC including the type locality of $A$. $m$. bervoetsi, Tsakalakuku ( $\left.5^{\circ} 51^{\prime} \mathrm{S} ; 17^{\circ} 23^{\prime} \mathrm{E}\right)$ and Kenge ( $\left.5^{\circ} 19^{\prime} \mathrm{S} ; 19^{\circ} 58^{\prime} \mathrm{E}\right)$; and from the island of Bufumira $\left(0^{\circ} 19^{\prime} \mathrm{S} ; 32^{\circ} 22^{\prime} \mathrm{E}\right)$ on Lake Victoria in Uganda (Figure 1$)$. Collections were attempted in Nigeria, in and around the village of Akaka $\left(6^{\circ} 27^{\prime} \mathrm{N} ; 3^{\circ} 24^{\prime} \mathrm{E}\right)$ in the Lagos area where A. m. nigeriensis was originally described [7], but were unsuccessful.

Tsakalakuku is situated in the tropical wet savannas region of Africa. The area is characterized by a succession of hills covered with grass fields and valleys occupied by forest galleries along streams. The climate comprises a dry and a rainy season of six months each. All other collection sites are located within the Congo-Guinean phytogeographic zone, characterized by a typical equatorial climate with two rainy seasons extending from March to June and from September to November (total rainfall around 1,500 mm per year).

Mosquito collections were conducted from July 2003 to April 2004 in Cameroon [12], in December 2003 in DRC and in October 2004 in Uganda. Anopheles moucheti specimens were visually sorted from other anophelines according to morphological identification keys [7,13]. All specimens were stored individually and kept at $-20^{\circ} \mathrm{C}$ until further analysis.

\section{DNA extraction and genotype scoring}

Genomic DNA was extracted from wings or legs of each individual mosquito as described earlier [12]. Morphological identification was confirmed through the recently developed PCR based assay [10]. Genotypes at 10 microsatellite loci were determined for the DRC $(\mathrm{N}=64$ in Tsakalakuku and $\mathrm{N}=11$ in Kenge) and Uganda ( $\mathrm{N}=57)$ samples as previously described [12].

\section{Data analysis}

Genetic diversity within samples and overall was measured at each locus by estimating allele richness $R s$, an unbiased estimator of the number of alleles in each sam- 


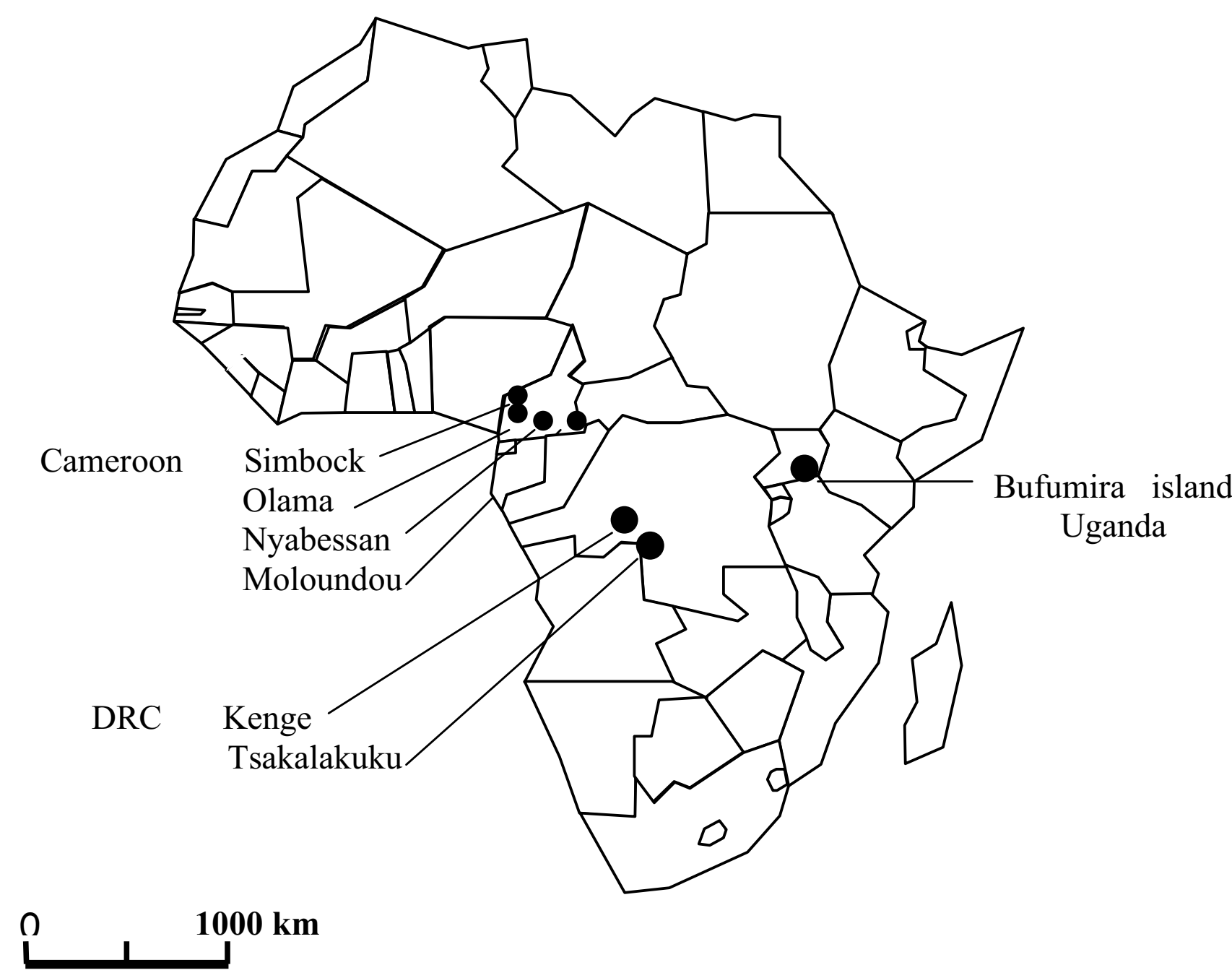

Figure I

A schematic map of Africa showing sampling sites for A. moucheti in Cameroon, Democratic Republic of Congo (DRC) and Uganda.

ple accounting for differences in sample sizes [14], and $\mathrm{He}$ [15], the unbiased expected heterozygosity under HardyWeinberg equilibrium (HWE), using the software FSTAT V2.9.3.2 [16]. Genotypic frequencies were tested against HWE for each locus in the pooled population and in each sample. Statistical significance was assessed by the exact probability test available in GENEPOP V3.2 [17]. Linkage disequilibrium between loci was tested by exact tests on contingency tables, also available in GENEPOP.

Genetic differentiation between populations was assessed by estimating Wright's F-statistics [18], calculated according to Weir \& Cockerham [19]. Statistical significance of Fst was assessed using G-based exact tests for genotypic differentiation [20], available in GENEPOP. The correlation between genetic and geographic distances, assuming isolation by distance, was assessed by the regression of pairwise Fst estimates on the logarithm (ln) of geographic distances between sampling sites [21], and tested by the Mantel test available in GENEPOP. A Bayesian approach was further implemented to infer the number of genetic clusters $(K)$ in the dataset without prior information on the sampling locations, using STRUCTURE 2.2 [22]. A model where the allele frequencies were correlated within populations was assumed ( $\lambda$ was set at 1 , the default value). The software was run with the option of admixture, allowing for some mixed ancestry within individuals, and $\alpha$ was allowed to vary. Twenty independent runs were done for each value of $K(\mathrm{~K}=1$ to 8$)$, with a burn-in period of 100,000 iterations and 100,000 replications. The method of Evanno et al [23] was used to determine the most likely number of clusters. This approach uses an 
ad hoc quantity, $\Delta K$, based on the second order rate of change of the likelihood function between successive values of $K$.

Because demographic instability such as recent population bottleneck and/or expansion might bias genetic differentiation estimates to a significant extent $[24,25]$, heterozygosity tests were used to test for Mutation-Drift Equilibrium (MDE) within each sample, as implemented in BOTTLENECK 1.2.02 [26]. At selectively neutral loci, the expected heterozygosities calculated from allele frequencies data $(\mathrm{He})$ and from the number of alleles and sample sizes $(\mathrm{Heq})$ are expected not to be significantly different in a population at MDE. Comparing $\mathrm{He}$ to $\mathrm{Heq}$ across loci, therefore, provides the basis for testing this hypothesis. If the population recently experienced a bottleneck, rare alleles will be rapidly lost and therefore Heq will decrease faster than $\mathrm{He}$. Thus, observing a significant number of loci with $\mathrm{He}>\mathrm{Heq}$ suggests the focal population recently experienced a bottleneck while the reverse trend (i.e., $\mathrm{He}<\mathrm{Heq}$ ) may suggest population expansion. Estimates of expected heterozygosity under MDE were calculated assuming a Stepwise Mutation Model (SMM) and a Two Phase Model (TPM) with 10-30\% indels larger than the repeat unit. Statistical significance of the deviation from MDE was assessed for each sample across all loci by the Wilcoxon signed ranks tests and sign tests available in BOTTLENECK.

Differences in effective population size (Ne) between samples might further increase estimates of genetic differentiation between populations because differences in $\mathrm{Ne}$ violates assumptions of the island model of population migration, assumed to hold true when devising F-statistics [19]. Estimates of "long-term" effective population size [15] were calculated for each sample based on the expected heterozygosity at each microsatellite locus assuming a SMM using the formula Ne $\mu=\left\{[1 /(1-\mathrm{He})]^{2}\right.$ $1\} / 8[15,27]$, where He is the expected heterozygosity under HWE and $\mu$ is the microsatellite mutation rate.

Because the average mutation rate does not vary much even between well separated species such as pigs $\left(7 \times 10^{-}\right.$ 5 , [28]) and mice $\left(4.5 \times 10^{-5},[29]\right)$, the value of $10^{-4}$ proposed by Lehmann et al [30] for Anopheles gambiae was conservatively adopted for estimating A. moucheti longterm Ne. Nevertheless, inferences were drawn on a relative scale, using the product of $\mathrm{Ne} \mu$ as a proxy of long-term $\mathrm{Ne}$ for each population, therefore alleviating any bias due to incorrect estimation of the mutation rate.

In all instances where multiple tests were conducted simultaneously, the sequential Bonferroni procedure [31] was applied to adjust the nominal significance level.

\section{Results \\ Genetic variability within populations}

A total of 355 mosquitoes of the A. moucheti group were analysed in this study, including 223 mosquitoes from Cameroon that were previously genotyped [12]. Of these, 64 specimens collected in Tsakalakuku (DRC) were A. $\mathrm{m}$. bervoetsi and the rest were A. m. moucheti. Genotypes at 10 microsatellites were determined. All loci amplified successfully in all A. m. moucheti populations and were highly polymorphic, showing between 11 (AM13) and 17 (AM5 and AM15) distinct alleles. By contrast, only six loci could be amplified in the A. m. bervoetsi sample, among which AM13 was not polymorphic (Table 1). Consequently, this population showed the lowest allele richness (even when only five polymorphic loci were considered), and lowest expected heterozygosity (Table 1 ), followed by the A. $m$. moucheti population collected from the island of Bufurima (Uganda). All mainland populations of A. $m$. moucheti showed similar average allele richness (range 5.53-6.66) and expected heterozygosity (range 0.771$0.833)$.

Hardy-Weinberg expectations were significantly rejected $(\mathrm{P}<0.001)$ for seven out of 10 loci when considering the pooled samples as belonging to a single panmictic population, with heterozygote deficits being evidenced at all loci, as expected when different gene pools are mixed. At the population level, 22 out of 65 tests did not conform to Hardy-Weinberg expectations after the multi-test analysis was taken into account. Significant deviation from HWE varied across loci in a population-dependent manner. The Uganda population from Bufumira island had the highest number of loci in departure from HWE ( 6 of 10) while the Kenge population had the fewest ( 1 of 10).

Exact tests for linkage disequilibrium within each of the seven populations resulted in three significant values out of 276 comparisons after correction by the Bonferroni procedure (two in Mouloundou (AM2-AM6, AM9-AM20) and one in Simbock (AM9-AM10)). No pair of loci appeared in linkage disequilibrium in more than one population, suggesting genetic independence between loci. When the test was performed in the pooled populations, two pairs of loci (AM2-AM16 and AM2-AM20) out of 45 possible combinations showed highly significant $P$ values $\left(<10^{-6}\right)$.

\section{Genetic differentiation between populations}

Table 2 shows Fst estimates for all pairwise population comparisons. Genotypic frequencies were highly significantly different among samples (G-test, $\mathrm{P}<0.001$ ). Low to moderate levels of genetic differentiation were measured among mainland populations of $A$. m. moucheti from Cameroon and DRC, with mean Fst estimates ranging $0.009-0.049(P<0.001)$. The island population of 
Table I: Genetic diversity at 10 microsatellite loci in Anopheles moucheti from Cameroon ${ }^{a}$, DRC and Uganda.

\begin{tabular}{|c|c|c|c|c|c|c|c|c|c|}
\hline \multirow[b]{2}{*}{ Locus } & & \multicolumn{4}{|c|}{ Cameroon $^{\mathrm{a}}$} & \multicolumn{2}{|c|}{ DRC } & \multirow{2}{*}{$\begin{array}{r}\text { Uganda } \\
\begin{array}{r}\text { Bufumira } \\
(2 n=114)\end{array}\end{array}$} & \multirow[b]{2}{*}{$\begin{array}{r}\text { All } \\
(2 n=710)\end{array}$} \\
\hline & & $\begin{array}{r}\text { Simbock } \\
(2 n=118)\end{array}$ & $\begin{array}{r}\text { Olama } \\
(2 n=1 / 2)\end{array}$ & $\begin{array}{l}\text { Nyabessan } \\
(2 n=108)\end{array}$ & $\begin{array}{r}\text { Mouloundou } \\
(2 n=108)\end{array}$ & $\begin{array}{r}\text { Kenge } \\
(2 n=22)\end{array}$ & $\begin{array}{r}\text { Tsakalakuku } \\
(2 n=128)\end{array}$ & & \\
\hline \multirow[t]{3}{*}{ AMI } & Rs & 5.99 & 6.30 & 5.35 & 6.92 & 5.87 & $N A$ & $4.4 I$ & 6.46 \\
\hline & $\mathrm{He}$ & 0.805 & 0.823 & 0.805 & 0.854 & 0.853 & - & 0.662 & 0.834 \\
\hline & Fis & +0.139 & +0.264 & +0.347 & +0.338 & +0.372 & - & -0.037 & +0.287 \\
\hline \multirow[t]{3}{*}{ AM2 } & Rs & 6.06 & 6.87 & 6.0 & 6.67 & 7.75 & 2 & 4.58 & 6.75 \\
\hline & $\mathrm{He}$ & 0.807 & 0.847 & 0.812 & 0.836 & 0.895 & 0.503 & 0.719 & 0.845 \\
\hline & Fis & +0.119 & +0.186 & +0.342 & +0.174 & +0.267 & -1 & +0.321 & +0.188 \\
\hline \multirow{3}{*}{ AM5 } & Rs & 8.06 & 7.22 & 8.63 & 7.37 & 5.70 & 3.39 & 5.76 & 8.87 \\
\hline & $\mathrm{He}$ & 0.881 & 0.862 & 0.898 & 0.870 & 0.723 & 0.639 & 0.772 & 0.906 \\
\hline & Fis & +0.150 & +0.018 & +0.069 & +0.168 & +0.758 & -0.027 & +0.355 & +0.21 \\
\hline \multirow[t]{3}{*}{ AM6 } & Rs & 7.24 & 6.40 & 7.33 & 7.13 & 3.72 & $N A$ & 2.69 & 7.00 \\
\hline & $\mathrm{He}$ & 0.872 & 0.826 & 0.870 & 0.850 & 0.671 & - & 0.482 & 0.847 \\
\hline & Fis & +0.283 & +0.298 & +0.263 & +0.202 & +0.605 & - & +0.700 & +0.382 \\
\hline \multirow[t]{3}{*}{ AM9 } & Rs & 6.54 & 6.58 & 7.80 & 5.85 & 5.38 & $N A$ & 2.31 & 6.63 \\
\hline & $\mathrm{He}$ & 0.762 & 0.800 & 0.875 & 0.785 & 0.745 & - & 0.201 & 0.785 \\
\hline & Fis & -0.026 & -0.011 & +0.042 & +0.039 & +0.152 & - & -0.074 & +0.137 \\
\hline \multirow[t]{3}{*}{ AMIO } & Rs & 4.28 & 4.14 & 5.49 & 4.73 & 5.00 & 1.94 & 4.31 & 4.85 \\
\hline & $\mathrm{He}$ & 0.704 & 0.698 & 0.790 & 0.764 & 0.775 & 0.260 & 0.636 & 0.738 \\
\hline & Fis & -0.065 & +0.028 & +0.110 & +0.019 & +0.205 & +0.107 & -0.159 & +0.139 \\
\hline \multirow[t]{3}{*}{ AMI3 } & Rs & 5.93 & 6.12 & 5.49 & 6.16 & 5.37 & 1 & 4.78 & 5.92 \\
\hline & $\mathrm{He}$ & 0.823 & 0.824 & 0.802 & 0.830 & 0.737 & - & 0.669 & 0.848 \\
\hline & Fis & +0.008 & +0.042 & +0.177 & +0.077 & -0.091 & - & -0.042 & +0.292 \\
\hline \multirow[t]{3}{*}{ AMI5 } & Rs & 7.10 & 6.85 & 8.21 & 7.17 & 6.00 & 6.13 & 1.60 & 7.85 \\
\hline & $\mathrm{He}$ & 0.820 & 0.822 & 0.869 & 0.818 & 0.834 & 0.825 & 0.083 & 0.844 \\
\hline & Fis & +0.188 & +0.094 & +0.049 & +0.119 & +0.263 & +0.193 & -0.025 & +0.264 \\
\hline \multirow[t]{3}{*}{ AMI 6} & Rs & 5.98 & 6.69 & 6.20 & 6.37 & 6.59 & 1.45 & 3.20 & 6.39 \\
\hline & $\mathrm{He}$ & 0.823 & 0.843 & 0.822 & 0.829 & 0.868 & 0.058 & 0.605 & 0.836 \\
\hline & Fis & +0.051 & +0.101 & +0.076 & +0.076 & +0.203 & +0.327 & +0.192 & +0.273 \\
\hline \multirow[t]{3}{*}{ AM20 } & Rs & 7.17 & 7.22 & 6.06 & 7.16 & 3.88 & $N A$ & 3.41 & 6.94 \\
\hline & $\mathrm{He}$ & 0.844 & 0.832 & 0.788 & 0.848 & 0.634 & - & 0.532 & 0.839 \\
\hline & Fis & +0.218 & +0.066 & +0.203 & +0.083 & +0.130 & - & +0.271 & +0.249 \\
\hline \multirow{3}{*}{$\begin{array}{l}\text { Mean across } \\
\text { all loci }\end{array}$} & Rs & 6.44 & 6.44 & 6.66 & 6.55 & 5.53 & 2.65 & 3.71 & 6.77 \\
\hline & $\mathrm{He}$ & 0.814 & 0.818 & 0.833 & 0.830 & 0.771 & 0.228 & 0.534 & 0.689 \\
\hline & Fis & +0.112 & +0.114 & +0.166 & +0.180 & +0.291 & -0.136 & +0.175 & NC \\
\hline
\end{tabular}

All: refers to populations pooled. $2 \mathrm{n}$, number of chromosomes scored; Rs, allele richness [14]; He, expected heterozygosity under Hardy-Weinberg equilibrium [5I]. Fis was calculated according to Weir \& Cockerham [19] and goodness of fit to Hardy-Weinberg equilibrium was estimated by the exact test available in Genepop 3.2 [17]. Bolded values: $\mathrm{P}<0.05$ after taking into account multiple tests [3I]. NA, No PCR product could be detected; -, irrelevant because no polymorphism was detected;NC, not computed. a Data adapted from [12].

Bufurima (Uganda) showed higher levels of differentiation with this core group, with pairwise Fst estimates in the range $0.167-0.223(\mathrm{P}<0.001)$. The highest levels of genetic differentiation were observed in all comparisons involving the A. $m$. bervoetsi sample collected in Tsakalakuku (DRC), with Fst estimates ranging 0.343-0.448 (P $<0.001)$.

In agreement with results based on Fst, the Bayesian cluster analysis showed that the most likely $\mathrm{K}$ value identified was $\mathrm{K}=3$. This corresponded to three distinct genetic clusters: (1) mainland A. m. moucheti from Cameroon and
DRC, (2) A. m. moucheti from Bufumira island in Uganda and (3) A. m. bervoetsi (Figure 2).

Because isolation by distance is likely to play a major role in shaping the distribution of genetic diversity across continuous habitats [21,32], only the mainland populations of A. m. moucheti from Cameroon and DRC (i.e. excluding the samples from the island of Bufurima and the A. m. bervoetsi sample from Tsakalakuku and focusing on "cluster 1 " described above) were used for the Mantel test. Positive and highly significant correlation $(\mathrm{P}<0.008$, Mantel test $)$ was found between genetic (Fst) and geographic dis- 
Table 2: Pairwise Fst estimates between $A$. moucheti populations from Cameroon ${ }^{\text {a }}$, DRC and Uganda.

\begin{tabular}{|c|c|c|c|c|c|c|c|}
\hline & & \multicolumn{4}{|c|}{ Cameroon $^{\mathrm{a}}$} & \multicolumn{2}{|c|}{ DRC } \\
\hline & & Simbock & Olama & Nyabessan & Mouloundou & Kenge & Tsakalakuku \\
\hline \multirow[t]{4}{*}{ Cameroon $^{\mathrm{a}}$} & Simbock & & & & & & \\
\hline & Olama & $0.011^{*}$ & & & & & \\
\hline & Nyabessan & $0.014^{*}$ & $0.009 *$ & & & & \\
\hline & Mouloundou & $0.028^{*}$ & $0.023^{*}$ & $0.017 *$ & & & \\
\hline \multirow[t]{2}{*}{ DRC } & Kenge & $0.049 *$ & $0.037^{*}$ & $0.040^{*}$ & $0.032^{*}$ & & \\
\hline & Tsakalakuku & $0.378^{*}$ & $0.372^{*}$ & $0.343^{*}$ & $0.346 *$ & $0.422^{*}$ & \\
\hline Uganda & Bufumira & $0.167^{*}$ & $0.172 *$ & $0.187^{*}$ & $0.168^{*}$ & $0.223^{*}$ & $0.448^{*}$ \\
\hline
\end{tabular}

$* \mathrm{P}<0.00$ I; DRC, Democratic Republic of Congo; a pairwise Fst estimates between Cameroon populations were already published in [12].

tances. Using the equation of the regression line of Fst on the logarithm of distance between sampling sites (Figure 3 ), the expected level of genetic differentiation between all mainland samples of A. m. moucheti and the A. m. moucheti sample from Bufurima island and A. m. bervoetsi, respectively were predicted under the hypothesis that geographic distance between populations was the main determinant of genetic differentiation. As can be graphically seen on Figure 3, the predicted Fst estimates were three to nine folds lower than the observed value for the Bufurima sample, and up to 8-25 folds lower than the observed value for the A. $m$. bervoetsi population. As such, distance alone contributed to less than $30 \%$ of the observed level of differentiation between the island A. m. moucheti sample from Bufurima and all other A. m. moucheti samples, while it explained less than $15 \%$ of the differentiation with the A. $m$. bervoetsi sample.

\section{Effective population size and demographic stability}

Estimates of long-term Ne were similar for all mainland $A$. $m$. moucheti populations (Table 3 ). These were signifi- cantly lower for the Bufurima island population and the A. $m$. bervoetsi sample. Calculation of the relative ratio of Ne $\mu$ compared to the A. m. moucheti population with the smallest effective population size (Bufumira island), showed that the estimates were five to nine folds higher for mainland populations of $A$. $m$. moucheti, whereas they were at least five folds lower for the A. m. bervoetsi sample. This demonstrates significant heterogeneity in effective population size between the different genetic clusters identified above.

Estimates of genetic differentiation and effective population size however are based on the assumption of MDE. Results of the heterozygosity tests (Table 4) did not reveal any evidence for departure from MDE in any of the mainland populations of $A$. m. moucheti, nor in the A. m. bervoetsi population. However, a consistent trend for lowerthan-expected heterozygosity (i.e., He<Heq) was evidenced for the Bufurima island population, suggesting recent demographic expansion.

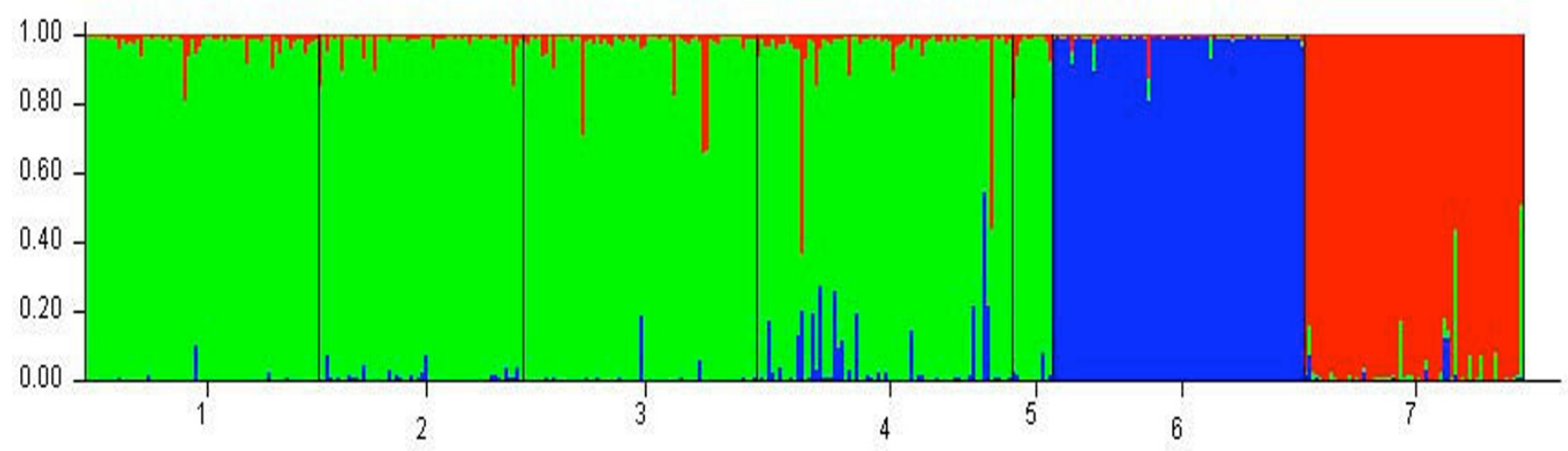

Figure 2

Bayesian cluster analysis using STRUCTURE [22]. Graphical representation of the data set for the most likely $K(K=3)$, where each colour corresponds to a suggested cluster and each individual is represented by a vertical bar. The numbers in the $\mathrm{X}$-axis correspond to a specific sample: I-Simbock, 2-Olama, 3-Nyabessan, 4-Mouloundou, 5-Kenge, 6-Uganda, 7-Tsakalakuku. The $\mathrm{Y}$-axis represents the probability of assignment of an individual to each cluster. 


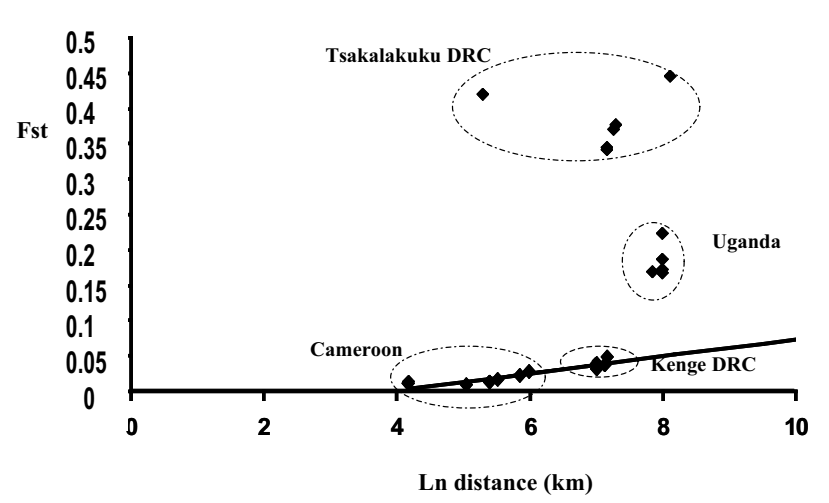

Figure 3

Correlation between average Fst estimates over 10 microsatellite loci and logarithm of geographic distance between collection sites for pairwise comparisons of seven $A$. moucheti populations from

Cameroon, DRC and Uganda. The name of each sampling site refers to comparisons involving these populations.

\section{Discussion}

In this study, six $A$. m. moucheti populations from different geographic locations and one $A$. $m$. bervoetsi population were compared for variation in polymorphism and allele distribution at 10 microsatellite loci. Successful amplification at each microsatellite locus was obtained for all A. $m$. moucheti specimens while only six loci could be amplified in the A. $m$. bervoetsi sample, one of which did not show any polymorphism, all specimens investigated showing the same single allele at a homozygous state. This result provides further support for speciation within the A. moucheti group of malaria vectors in Central Africa and reflects, for the first time, genome-wide differentiation between A. m. moucheti and A. m. bervoetsi. Indeed, although the exact cytological location of the microsatellite markers is not known yet, linkage disequilibrium analysis revealed no evidence for genetic linkage between loci, suggesting they provided independent replicates for genome-wide estimation of genetic differentiation between samples. Successful amplification of microsatellite alleles was demonstrated among closely related species such as humans and great apes [33] as well as between sibling species of wasps [34] and members of anophelines species complexes [35,36]. However, the proportion of loci developed for one species that can amplify in another decreases rapidly with increasing evolutionary distance $[37,38]$. These results are, therefore, in straight agreement with previous studies based on morphological $[7,8]$ and molecular data (mtDNA CytB and rDNA ITS; [10]), prompting for elevation of $A$. $m$. bervoetsi to full specific rank as a closely related sibling species of $A$. m. moucheti.

Linkage disequilibrium analysis further ruled out the hypothesis that the fairly high number of loci which were found out of HWE in several collections was indicative of inbreeding and/or population subdivision (within samples). If this was the case, genome-wide signatures of departure from HWE and high linkage disequilibrium between loci should be evidenced, because members of the different sub-populations would have different probabilities to carry certain combinations of alleles [30]. Such trends were not observed in the dataset, suggesting null alleles, rather than population subdivision may be responsible for the deviations observed. Null alleles are a common finding in anophelines' population genetics studies [39-41]. Because the frequencies of such null alleles might differ between sub-populations, they contribute to the overall genetic differentiation between populations. Fst estimates between populations were therefore calculated using all the information available from all loci and all samples.

Fst estimates recorded between $A$. $m$. bervoetsi and each of A. $m$. moucheti populations were very high and statistically significant (Fst $>0.34, \mathrm{P}<0.001$ ), falling in the upper range of values reported between well separated anophelines sibling species using various molecular markers [42$44]$. This result, as well as results from the Bayesian analysis clearly identified $A$. $m$. bervoetsi as a genetically distinct entity within the A. moucheti group. Accordingly, it

Table 3: Long-term Ne estimates based on genetic diversity (expected heterozygosity) in each collection site, assuming microsatellite loci follow an SMM (see text).

\begin{tabular}{|c|c|c|c|c|c|}
\hline \multicolumn{2}{|c|}{ Collection site } & \multirow{2}{*}{$\begin{array}{c}\mathrm{He} \\
0.814\end{array}$} & \multirow{2}{*}{$\begin{array}{c}\mathrm{Ne}( \pm \mathrm{SD}) \\
42,396 \pm 10,934\end{array}$} & \multirow{2}{*}{$\begin{array}{l}\mathrm{Ne \mu} \\
3.488\end{array}$} & \multirow{2}{*}{$\begin{array}{l}\text { RR } \\
7.7: 1\end{array}$} \\
\hline Cameroon & Simbock & & & & \\
\hline & Olama & 0.818 & $40,670 \pm 10,651$ & 3.649 & $8.1: 1$ \\
\hline & Nyabessan & 0.833 & $53,046 \pm 14,269$ & 4.357 & $9.3: 1$ \\
\hline & Mouloundou & 0.830 & $45,606 \pm 12,092$ & 4.20 & $9.3: 1$ \\
\hline \multirow[t]{2}{*}{ DRC } & Kenge & 0.771 & $36,90 \mathrm{I} \pm 24,36 \mathrm{I}$ & 2.259 & $5: 1$ \\
\hline & Tsakalakuku & 0.228 & $5,230 \pm 1,602$ & 0.085 & $0.188: 1$ \\
\hline Uganda & Bufumira & 0.534 & $7,983 \pm 2,316$ & $0.45 I$ & I \\
\hline
\end{tabular}

He, unbiased heterozygosity [15]; Ne, mean effective population size calculated across all loci ( \pm standard deviation); $\mu$, mutation rate; RR, relative ratio of $\mathrm{Ne} \mu$ compared to the $A$. $m$. moucheti population with the smallest effective population size (Bufurima island). 
Table 4: Estimates of P-value for the heterozygosity tests for each population of the A. moucheti group.

\begin{tabular}{|c|c|c|c|c|c|c|}
\hline \multirow[t]{2}{*}{ Collection site } & & & \multicolumn{3}{|c|}{ TPM } & \multirow[t]{2}{*}{ SMM } \\
\hline & & & $70 \%^{\mathrm{a}}$ & $80 \%^{a}$ & $90 \%^{\mathrm{a}}$ & \\
\hline \multirow[t]{12}{*}{ Cameroon } & Simbock & $\mathrm{He}>\mathrm{Heq}$ & 7 & 6 & 4 & 3 \\
\hline & & Sign test & 0.360 & 0.619 & 0.192 & 0.066 \\
\hline & & Wilcoxon test & 0.322 & 0.695 & 0.625 & $0.024^{*}$ \\
\hline & Olama & $\mathrm{He}>\mathrm{Heq}$ & 7 & 6 & 5 & 3 \\
\hline & & Sign test & 0.377 & 0.609 & 0.396 & 0.067 \\
\hline & & Wilcoxon test & 0.275 & I & 0.492 & 0.084 \\
\hline & Nyabessan & $\mathrm{He}>\mathrm{Heq}$ & 8 & 8 & 6 & 4 \\
\hline & & Sign test & 0.158 & 0.149 & 0.608 & 0.184 \\
\hline & & Wilcoxon test & $0.010^{*}$ & $0.016 *$ & 0.625 & 0.432 \\
\hline & Mouloundou & $\mathrm{He}>\mathrm{Heq}$ & 7 & 5 & 4 & 2 \\
\hline & & Sign test & 0.362 & 0.376 & 0.183 & $0.015^{*}$ \\
\hline & & Wilcoxon test & 0.557 & 0.846 & 0.275 & $0.019 *$ \\
\hline \multirow[t]{6}{*}{ DRC } & Kenge & $\mathrm{He}>\mathrm{Heq}$ & 7 & 7 & 7 & 7 \\
\hline & & Sign test & 0.355 & 0.395 & 0.351 & 0.376 \\
\hline & & Wilcoxon test & $0.019 *$ & 0.105 & 0.432 & 0.557 \\
\hline & Tsakalakuku & $\mathrm{He}>\mathrm{Heq}$ & 4 & 4 & 4 & 3 \\
\hline & & Sign test & 0.212 & 0.212 & 0.225 & 0.575 \\
\hline & & Wilcoxon test & 0.625 & 0.625 & 0.625 & 1 \\
\hline \multirow[t]{3}{*}{ Uganda } & Bufurima & $\mathrm{He}>\mathrm{Heq}$ & 2 & 2 & 1 & I \\
\hline & & Sign test & $0.015^{*}$ & $0.015^{*}$ & $0.002^{* *}$ & $0.002^{* *}$ \\
\hline & & Wilcoxon test & 0.032 & $0.010 *$ & $0.003^{* *}$ & $0.002^{\text {** }}$ \\
\hline
\end{tabular}

TPM, two-phase mutation model with a \% single step mutation; SMM, stepwise mutation model.

$\mathrm{He}>\mathrm{Heq}$, number of loci with $\mathrm{He}>\mathrm{Heq}$ (out of 10 loci tested in each sample, except the $A$. $m$. bervoetsi sample from Tsakalakuku where only 5 polymorphic loci were considered). $* \mathrm{P}<0.05$ and $* * \mathrm{P}<0.01$ (two tails $\mathrm{P}$-values for deviation from MDE) after correction for multiple testing.

seems reasonable to consider this taxon as a full, independently evolving species within the A. moucheti group and, henceforth, to refer to this species as Anopheles bervoetsi. However, considering that $A$. bervoetsi has never been reported to occur in sympatry with A. moucheti s.s., nor outside of its type locality, this assertion should be validated through traditional crossing experiments, which are yet impossible to implement because members of the A. moucheti group have never been maintained successfully under insectary conditions. Preliminary analysis of 237 field-collected A. bervoetsi specimens after ELISA detected three females infected by Plasmodium falciparum (Antonio-Nkondjio C, Ndo C, Awono-Ambene HP and Simard F, unpublished). Although incrimination of this species as a malaria vector through dissection of its salivary gland still has to be processed, this points to a possible and previously unrecognized role of this mosquito in malaria transmission in Central Africa.

Significant isolation by distance was revealed between mainland A. m. moucheti populations from Cameroon and DRC, separated by distances $>1,000 \mathrm{~km}$ (Figure 1), suggesting continuous habitat suitability for $A$. moucheti in these forested environments. Extrapolating the level of differentiation expected under the sole influence of geographical distance between mainland populations and the A. m. moucheti population collected on the island of
Bufurima on Lake Victoria (Uganda) showed that the observed level of differentiation was three to nine folds higher than expected. Such high Fst estimates probably reflect the contribution of large water bodies separating this island population from mainland ones, acting as a barrier to gene flow by restricting opportunities for migration between populations, as was demonstrated for $A$. gambiae in this area [41] and elsewhere $[36,45,46]$. Moreover, significant differences in effective population sizes $(\mathrm{Ne})$ were demonstrated, the island population of Bufurima showing significantly lower Ne than its mainland counterparts, and these might further increase Fst estimates [47]. Although $\mathrm{Ne}$ estimates based on He are criticizable because they rely on a number of assumptions including correct estimation of microsatellite mutation rate and mutation model, populations at MDE and selective neutrality of the loci, the comparison of $\mathrm{Ne} \mu$ on a relative scale allowed relieving some of these assumptions. Lower effective population size on the islands of Lake Victoria was indeed demonstrated for A. gambiae compared to neighbouring mainland populations [41] and the results presented here suggest the same probably applies within the A. moucheti group. As mentioned above however, estimates of Ne derived from He are sensitive to deviation from MDE. No significant deviation from MDE was evidenced within A. m. moucheti populations, although, to some extent, trends for recent population expansion were 
revealed for the island population of Bufurima. Colonization of Lake Victoria islands by anthropophilic malaria vectors probably followed initial human settlements on these islands in the early 1900s $[41,48]$. Initial founder effect might have occurred at that time but experimental studies and simulations have shown such events are only detectable for a small number of generations before a new equilibrium is reached, especially when considering molecular markers with high mutation rates such as microsatellite loci $[26,49]$. Inferences suggesting population expansion are generally more robust but still need to be ascertained through in-depth investigations [25].

Clearly, a more comprehensive picture of the genetic structure and distribution of genetic diversity within and among natural populations of members of the A. mouchet group of malaria vectors would have been obtained with the inclusion in this study of specimens of $A$. m. nigeriensis. However, as mentioned above, collections conducted in and around the type locality of this species were unsuccessful. Earlier investigations allowed collection of a few representative specimens [10] but sample sizes were far too small to allow reliable microsatellite allelic frequencies assessment. The Lagos area has recently undergone significant levels of anthropogenic environmental reshaping and urban expansion [50] and this might have led to a significant drop in $A$. m. nigeriensis populations, as was observed for A. m. moucheti in areas of southern Cameroon [4]. As formerly highlighted [6], the availability of PCR-based diagnostic tools and other molecular markers and their increased use in routine entomological surveys might allow more refined assessments of the diversity, geographic distribution ranges and relative epidemiological importance of the distinct anopheline species that constitute the extraordinary diverse and fluctuating malaria vector system in Africa. Such knowledge is of paramount importance for a comprehensive, efficient and sustainable implementation of vector control as a means to alleviate the malaria burden in Africa.

\section{Conclusion}

In conclusion, this study provides strong support for considering A. $m$. bervoetsi as a full-rank, genetically independent, species within the A. moucheti group of malaria vectors. The species should henceforth be named Anopheles bervoetsi. However, its epidemiological role as a vector of human malaria parasites still deserves further investigation because roughly nothing is known to date on its biology and behaviour. Isolation by distance seems to be the major factor shaping A. moucheti s.s. populations' genetic structure throughout its distribution range across forested areas of Central Africa but significant geographical barriers to gene flow exist, as evidenced from reduced effective population size and high levels of genetic differentiation observed in a population collected from an island on Lake
Victoria. Such genetically isolated populations in a geographically confined environment might be of considerable interest for a safe assessment of new and innovative vector control strategies aiming at population suppression and/or replacement, such as those based on the release of sterile or otherwise genetically altered mosquitoes.

\section{Authors' contributions}

CAN was involved in the study design and implementation, conducted field sampling, microsatellite genotyping and data analysis, prepared and drafted the manuscript. FS supervised the study conception and design, contributed to data analysis and drafted the manuscript. CN participated to field sampling in Cameroon and microsatellite genotyping. LM organized and greatly contributed to sampling in Uganda. PK was involved in molecular analysis and helped with markers selection resources. PAA and DF were involved in the conception of the study and revised the manuscript.

\section{Acknowledgements}

We are indebted to E. Mazambi and F. Watsenga of the Institut National de Recherche Biomédicale (INRB), Kinshasa, DRC; F. Senfuka of the Uganda Virus Research Institute (UVRI) and G. Ollivier of the French Foreign Office in DRC for valuable help during mosquito collections. This work was supported by grants no. A20727 and A60347 from the UNICEF/UNDP/World Bank/WHO Special Programme for Research and Training in Tropical Diseases (TDR) to C.A.N and the French Institut de Recherche pour le Développement (IRD/UROI6).

\section{References}

I. WHO/UNICEF/RBM: World Malaria Report 2005. In WHOI HTM/MAL/2005. I I 02 World Health Organization, Geneva; 2005.

2. Njan Nloga A, Robert V, Toto JC, Carnevale P: Anopheles moucheti, vecteur principal du paludisme au sud-Cameroun. Bulletin de Liaison et de Documentation de I'OCEAC 1993, 26:63-67.

3. Antonio-Nkondjio C, Awono-Ambene P, Toto JC, Meunier JY, Zebaze-Kemleu S, Nyambam R, Wondji CS, Tchuinkam T, Fontenille $\mathrm{D}$ : High malaria transmission intensity in a village close to Yaoundé, the capital city of Cameroon. J Med Entomol 2002, 39:330-355.

4. Antonio-Nkondjio C, Simard F, Awono-Ambene P, Ngassam P, Toto JC, Tchuinkam T, Fontenille D: Malaria vectors and urbanisation in the equatorial forest region of south Cameroon. Trans $R$ Soc Trop Med Hyg 2005, 99:347-354.

5. Antonio-Nkondjio C, Kerah Hinzoumbe C, Simard F, AwonoAmbene $P$, Tchuinkam T, Fontenille D: Complexity of the malaria vectorial system in Cameroon: Contribution of secondary vectors to malaria transmission. J Med Entomol 2006, 43: $|2| 5-|22|$.

6. Fontenille D, Simard F: Unravelling complexities in human malaria transmission dynamics in Africa through a comprehensive knowledge of vectors populations. Comp Immun Microbiol Infect Dis 2004, 27:357-375.

7. Gillies MT, De Meillon B: The Anophelinae of Africa South of the Sahara (Ethiopian zoogeographical region) 2nd edition. Publications of the South African Institute for Medical Research, Johannesburg; 1968.

8. Brunhes J, Le Goff G, Manga L, Geoffroy B: Anophèles afro-tropicaux. IV - Mise au point sur les espèces et sous-espèces du groupe Anopheles (Cellia) moucheti; réhabilitation d'An. (C.) multicinctus et d'An. (Cellia) garnhami basilewskyi. Annales de la Société Entomologique de France 1998, 34:397-405.

9. Antonio-Nkondjio C, Simard F, Cohuet A, Fontenille D: Morphological variability in Anopheles moucheti is not indicative of speciation: evidences from sympatric south Cameroon populations. Infect Genet Evol 2002, 2:69-72. 
10. Kengne P, Antonio-Nkondjio C, Awono-Ambene HP, Simard F, Awolola TS, Fontenille D: Molecular differentiation of three closely related members of the mosquito species complex, Anopheles moucheti, by mitochondrial and ribosomal DNA polymorphism. Med Vet Entomol 2007, 2 I : I77-I82.

II. Annan Z, Kengne P, Berthomieu A, Antonio-Nkondjio C, Rousset F, Fontenille $D$, Weill $M$ : Isolation and characterisation of polymorphic microsatellite markers from the mosquito Anopheles moucheti, malaria vector in Africa. Mol Ecol Notes 2003, 3:56-57.

12. Antonio-Nkondjio C, Ndo C, Awono-Ambene P, Ngassam P, Fontenille $D$, Simard F: Population genetic structure of the malaria vector $A$. moucheti in south Cameroon forest region. Acta Trop 2007, 1 01:61-68.

13. Gillies MT, Coetzee M: A supplement to the Anophelinae of Africa south of the Sahara Publications of the South African Institute for Medical Research, Johannesburg; 1987.

14. El Mousadik A, Petit R: High level of genetic differentiation for allelic richness among populations of the argan tree (Argania spinosa L.) Skeels endemic to Morocco. Theoret Appl Genet 1996, 92:832-839.

15. Nei M: Molecular evolutionary genetics. Colombia University press, New York; 1987.

16. Goudet J: FSTAT version 2.9.3.2. A computer software to calculate F-statistics. J Hered 1995, 86:485-486.

17. Raymond M, Rousset F: GENEPOP, Version I.2. A population genetics software for exact tests and ecumenicism. J Hered 1995, 86:248-249.

18. Wright S: Evolution and Genetics of populations. Variability within and among natural populations. Volume 4. Chicago: University of Chicago press; 1978.

19. Weir BS, Cockerham CC: Estimating F-statistics for the analysis of population structure. Evolution I984, 38: I358-I 370.

20. Goudet J, Raymond M, De Meeüs T, Rousset F: Testing differentiation in diploid populations. Genetics 1996, I44:1933-1940.

21. Rousset F: Genetic differentiation and estimation of gene flow from F-statistics under isolation by distance. Genetics 1997, | 45: $1219-1228$

22. Pritchard JK, Stephens M, Donnelly P: Inference of population structure using multilocus genotype data. Genetics 2000 , I 55:945-959.

23. Evanno G, Regnaut S, Goudet J: Detecting the number of clusters of individuals using the software STRUCTURE: a simulation study. Mol Ecol 2005, I 4:26I I-2620.

24. Lehmann T, Hawley WA, Grebert H, Danga M, Atieli F, Collins FH: The rift valley complex as a barrier to gene flow for Anopheles gambiae in Kenya. J Hered 1999, 90:6 13-621.

25. Donnelly MJ, Licht MC, Lehmann T: Evidence for a recent population expansion in the malaria vectors Anopheles arabiensis and Anopheles gambiae. Mol Biol Evol 200I, I 8: I 353-1364.

26. Cornuet JM, Luikart G: Description and power analysis of two tests for detecting recent population bottlenecks from allele frequency data. Genetics 1996, I44:2001-2014.

27. Otha T, Kimura M: A model of mutation appropriate to estimate the number of electrophoretically detectable alleles in a finite population. Genet Res 1973, 22:201-204.

28. Ellegren $\mathrm{H}$ : Mutation rates at porcine microsatellite loci. Mamm Genomes 1995, 6:376-377.

29. Deitrich W, Katz H, Lincoln SE, Shin SS, Friedman J, Dracopoli NC, Lander ES: A genetic map of the mouse suitable for typing intraspecific crosses. Genetics 1992, I 3 I:423-447.

30. Lehmann T, Hawley WA, Grebert H, Collins FH: The effective population size of Anopheles gambiae in Kenya: implications for population structure. Mol Biol Evol 1998, 15:264-276.

31. Holm S: A simple sequentially rejective multiple test procedure. Scand J Stat 1979, 6:65-70.

32. Slatkin M: Gene flow and population structure. Ecological genet ics 1994:3-17.

33. Bowcock AM, Ruiz-Linares A, Tomfohrde J, Minch E, Kidd JR, CavalliSforza LL: High resolution of human evolutionary trees with polymorphic microsatellites. Nature 1994, 368:455-457.

34. Estoup A, Rousset F, Michalakis Y, Cornuet JM, Adriamanga M, Guyomard R: Comparative analysis of microsatellite and allozyme markers: a case study investigating microgeographic differentiation in brown trout (Salmo trutta). Mol Ecol 1998, 7:339-353.
35. Kamau L, Lehmann T, Hawley WA, Orago ASS, Ke Z, Cornel A, Collins $\mathrm{FH}$ : Use of short tandem repeats for analysis of genetic variability in sympatric populations of An. gambiae and An. arabiensis. Heredity 1998, 80:675-682

36. Simard F, Fontenille D, Lehmann T, Girod R, Brutus L, Gopaul R, Dournon C, Collins FH: High amounts of genetic differentiation between populations of the malaria vector Anopheles arabiensis from west Africa and eastern outer islands. Am J Trop Med Hyg 1999, 60:1000-1009.

37. Irwin DM, Kocher TD, Wilson AC: Evolution of the cytochrome b gene of mammals. J Mol Evol I991, 32:128-44.

38. Primmer $\mathrm{CR}$, Moller AP, Ellegren $\mathrm{H}$ : A wide range survey of crossspecies microsatellite amplification in birds. Mol Ecol 1996, 5:365-378.

39. Donnelly MJ, Cuamba N, Charlwood JD, Collins FH, Townson H: Population structure in the malaria vector, Anopheles arabiensis Patton in East Africa. Heredity 1999, 83:408-4I7.

40. Lehmann T, Licht M, Elissa N, Maega BT, Chimumbwa JM, Watsenga FT, Wondji CS, Simard F, Hawley WA: Population structure of Anopheles gambiae in Africa. I Hered 2003, 94: I33-147.

4I. Kayondo JK, Mukwaya GL, Stump A, Michel AP, Coulibaly MB, Besansky NJ, Collins FH: Genetic structure of Anopheles gambiae populations on islands in northwestern Lake Victoria, Uganda. Malar J 2005, 4:I-I3.

42. Besansky NJ, Lehmann T, Fahey GT, Fontenille D, Braack LE, Hawley WA, Collins FH: Patterns of mitochondrial variation within and between African malaria vectors, Anopheles gambiae and An. arabiensis, suggest extensive gene flow. Genetics 1997, 147:1817-1828.

43. Awono-Ambene HP, Simard F, Antonio-Nkondjio C, Cohuet A Kengne $P$, Fontenille $D$ : Multilocus enzyme electrophoresis supports speciation within the Anopheles nili group of Malaria vectors in Cameroon. Am J Trop Med Hyg 2006, 75:656-658.

44. Slotman MA, Tripet F, Cornel AJ, Meneses CR, Lee $Y$, Reimer LJ, Thiemann TC, Fondjo E, Fofana A, Traore SF, Lanzaro GC: Evidence for subdivision within the $M$ molecular form of Anopheles gambiae. Mol Ecol 2007, I 6:639-649.

45. Reimer LJ, Tripet F, Slotman M, Spielman A, Fondjo E, Lanzaro GC: An unusual distribution of the kdr gene among populations of Anopheles gambiae on the island of Bioko, Equatorial Guinea. Insect Mol Biol 2005, I 4:683-688

46. Moreno M, Salgueiro P, Vicente JL, Cano J, Berzosa PJ, Lucio A Simard F, Caccone A, Do Rosario VE, Pinto J, Benito A: Genetic population structure of Anopheles gambiae in Equatorial Guinea. Malar 」 2007, 6:137.

47. Nei M, Chesser RK: Estimation of fixation indices and gene diversities. Ann Hum Genet 1983, 47:253-259.

48. [http://www.american.edu/TED/Victoria.htm]

49. Spencer CC, Neigel JE, Leberg PL: Experimental evaluation of the usefulness of microsatellite DNA for detecting demographic bottlenecks. Mol Ecol 2000, 9:1517-1528.

50. Cohen B: Urbanization in developing countries: Current trends, future projections, and key challenges for sustainability. Technology in Society 2006, 28:63-80.

51. Nei M: Estimation of average heterozygosity and genetic distance from a small number of individuals. Genetics 1978 , 89:583-590.

Publish with Bio Med Central and every scientist can read your work free of charge

"BioMed Central will be the most significant development for disseminating the results of biomedical research in our lifetime. "

Sir Paul Nurse, Cancer Research UK

Your research papers will be:

- available free of charge to the entire biomedical community

- peer reviewed and published immediately upon acceptance

- cited in PubMed and archived on PubMed Central

- yours - you keep the copyright 